\title{
Demographics of glyphosate-resistant and susceptible Italian ryegrass populations from Paraná
}

Fortunato D. B. Pagnoncellia* ${ }^{*}$, Michelangelo M. Trezzi ${ }^{\mathrm{a}} \odot$, Helis M. Salomão ${ }^{\mathrm{a}} \odot$, Katia C. Hartmann ${ }^{\mathrm{a}} \odot$, Patricia B. Pereira $^{\mathrm{a}} \odot$, Jose L. Gonzalez-Andujar ${ }^{\mathrm{b}}\left({ }_{0}\right.$

a UTFPR, Departament of Agronomy, Pato Branco, Paraná, Brazil. ' IAS/CSIC, Department of Weed Agroecolgy, Córdoba, Andalusia, España.

\begin{abstract}
Italian ryegrass (Lolium multiflorum $\mathrm{L}$.) has become notorious due to glyphosate resistance evolution. To study the demography of susceptible and glyphosate-resistant Italian ryegrass populations, several experiments were conducted in the grower's field to evaluate seedling emergence, survival and reproductive traits patterns in three cohorts, and the effect of density on seed production. Results showed that seedling emergence is fast, and under suitable environmental conditions, it can happen within 30 -days. Lower plant survival was observed in the first two cohorts $(2 \%$ and $3 \%$, respectively) compared to the last (13\%). A larger number of spikes (spk) per plant (pl) was observed in plants of the first two cohorts (50.34
\end{abstract}

and $47.02 \mathrm{spk} \mathrm{pl}^{-1}$, respectively) in comparison to the last one (26 spk pl-1); however, the third cohort presented a higher potential for flower (flwrs) production per spikelets (spklt) (13.5 flwrs spklt ${ }^{-1}$ ) in detriment to the first two (11.9 and 12.12 flwrs spklt ${ }^{-1}$ ). Fecundity was 20,300 and 13,830 seeds $\mathrm{pl}^{-1}$ for susceptible and glyphosate-resistant plants, respectively, and presented density-dependent regulation. A knowledge of Italian ryegrass's demographic parameters provides valuable information for identifying particularly vulnerable life-history processes and developing population dynamics models that can contribute to designing more rational control strategies.

Keywords: Lolium multiflorum L.; Seedling Emergence; Seedling Survival; Seed Production; Cohort

Journal Information:

ISSN - 2675-9462

Website: http://awsjournal.org

Journal of the Brazilian Weed Science Society

How to cite: Pagnoncelli FDB, Trezzi MM, Salomão HM, Hartmann KC, Pereira PB, Gonzalez-Andujar, JL. Demographics of glyphosateresistant and susceptible Italian ryegrass populations from Paraná. Adv Weed Sci. 2021;39:e02100011. https://doi.org/10.51694/AdvWeedSci/2021;39:00011

\section{Approved by: \\ Editor in Chief: Carlos Eduardo \\ Schaedler \\ Associate Editor: José Barbosa dos Santos}

Conflict of interest: The authors declare no conflict of interest regarding the publication of this manuscript.

Received: July 6, 2020

Approved: March 9, 2021

* Corresponding author: <fpagnoncelli@outlook.com>

\section{(c) (1)}

This is an open-access article distributed under the terms of the

Creative Commons Attribution License, which permits unrestricted use, distribution, and reproduction in any medium, provided that the original author and source are credited.

Copyright: 2021

\section{Introduction}

Italian ryegrass (Lolium multiflorum Lam.) is an annual plant and a native of Southern Europe and currently distributed in temperate and humid subtropical climate regions worldwide (Terrel, 1968). Italian ryegrass has high biomass accumulation; thus, it is used as forage production in integrated systems and as soil cover in conservation ones. As a weed, it is highly competitive, especially with winter cereals, and can reduce the wheat grain yield by up to $90 \%$ (Trusler et al., 2007). Italian ryegrass presents a very high fecundity reaching 44,000 seeds plant $^{-1}$, providing natural seedbank replenishment (Bararpour et al., 2017).

Unfortunately, Italian ryegrass control is mainly based on herbicide applications. Successive applications of the herbicide with the same mode of action (MOA) increase resistant plants' selection pressure and promote the spread of resistance. Nowadays, ryegrass is resistant to herbicides from eight different modes of action in 12 countries (Heap, 2020). In Brazil, Italian ryegrass has evolved resistance to herbicide from three modes of action, including enolpyruvylshikimate-phosphate synthase (EPSPS), acetolactate synthase (ALS), and acetyl-CoA carboxylase (ACCase) inhibitor herbicides (Weed Science, 2020). Furthermore, and there are also cases of multiple resistances involving them. Italian ryegrass has evolved resistance to herbicides commonly used in winter cereal crops in Brazil, which increases the complexity of weed management in such crops. Therefore, a better understanding of weed biology can help identify the most vulnerable stages of the plant life cycle, thus adopting more efficient management strategies.

Knowledge of weed biology is essential for improving integrated weed management. While there is considerable information on the biology of congeneric Lolium rigidum (Gonzalez-Andujar, Fernandez-Quintanilla, 2004), little is known about the demography of L. multiflorum, most of these studies have been conducted in greenhouses, evaluating biomass accumulation and seed production (Vargas et al., 2005; Fernández-Moreno et al., 2017). Moreover, understanding weed demographic parameters enables studies of population dynamics to make projections of Italian ryegrass populations (Gonzalez-Andujar et al., 2010). Weed demographic studies have been conducted with other species, such as Conyza bonariensis and Salsoa australis (Borger et al., 2009; Zambrano-Navea et al., 2018). These authors observed behavioral differences of plants according to the season of establishment on some demographic parameters, such as emergence, survival, and seed production. 
The study of demographic parameters of populations susceptible and resistant to herbicides is an important strategy to understand the behavior and differences between populations. Several studies have shown the difference in behavior between susceptible and resistant plants to herbicides (Giacomini et al., 2014; Yanniccari et al., 2016). The objective of this study was to gain insights into the demography of glyphosateresistance and glyphosate susceptible Italian ryegrass populations, having established the hypothesis that there are demographic differences between them.

\section{Material and methods}

\subsection{Study area and populations}

Field experiments were conducted between March and November 2018 in the Experimental Area at the Federal University Technology - Paraná Campus Pato Branco (Brazil) (26¹0'32.6”S 5241'11.2”W, Alt. 720m). The region's climate is a Humid Subtropical Cfa, according to the KöppenGeiger (Peel et al., 2007). The environmental conditions during the experiments are shown in Figure 1, and the soil attributes in Table 1.

Italian ryegrass seeds were collected on the grower's field of the Southwest Region of Paraná ( $26^{\circ} 19^{\prime} S 52^{\circ} 46^{\prime} \mathrm{W}$ ).

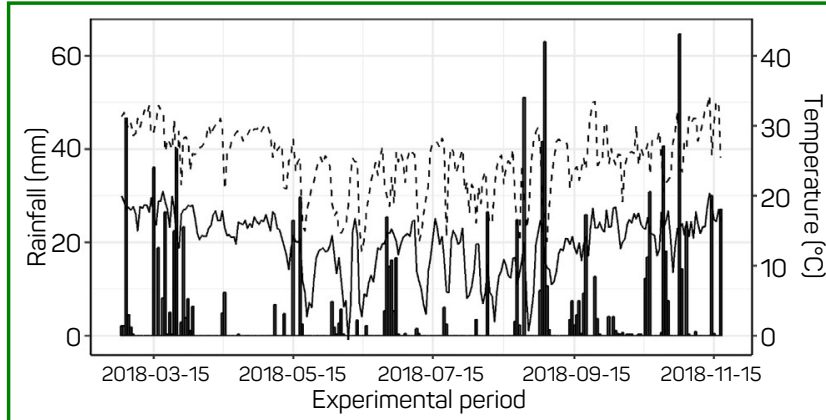

Figure 1 - Rainfall (-), minimum (--) and maximum temperature (-) during the experimental period in 2018 in Pato Branco region. The square (-) show the implementation date of each cohort in the field. The source of environmental data is Simepar (Paraná Meteorological System).

\begin{tabular}{l} 
Table 1 - Properties of the soil used in the experiment. \\
Textural composition \\
\hline Clay
\end{tabular}

1/ Organic matter ( $\left.\mathrm{g} \mathrm{dm}^{-3}\right) ;{ }^{2 /}$ Phosphorous (mg dm $\mathrm{dm}^{-3}$; ${ }^{3 /}$ Potassium (cmolc $\left.\mathrm{dm}^{-3}\right) ;{ }^{4 /}$ Cation exchange capacity; ${ }^{5 /} \mathrm{pH}$ of soil; ${ }^{6 /}$ Exchangeable acidity (cmolc $\mathrm{dm}^{-3}$ ).
Seeds of the glyphosate-resistant Italian ryegrass population were collected from an area with a long history of herbicide resistance ( $>15$ years), and the glyphosatesusceptible Italian ryegrass population was harvested in an area close by $<2 \mathrm{~km}$ with a known history of susceptibility to glyphosate. To check for contamination of susceptible seeds among resistant seeds or resistant seeds among susceptible seeds, seed samples were sown in pots $\left(4,500 \mathrm{~cm}^{3}\right)$; when seedlings were at the three-tiller stage, glyphosate $(720 \mathrm{~g}$ $\mathrm{ha}^{-1}$ ) was applied. Ryegrass plant survival was evaluated at 28 days after the application, and it was not observed any dead plant, confirming that the seed populations did not show any contamination.

\subsection{Seedling emergence pattern}

The study was conducted in a randomized block design (RBD) with eight replications. The area selected for this study had a history of absence of presence of plants of the genus Lolium. In this study, susceptible and resistant populations to glyphosate as treatments have been compared. In each treatment, eight microplots of $0.5 \times 0.5$ $\mathrm{m}$ were sown with 50 seeds uniformly distributed over the soil surface and covered with a thin layer of soil $(<1 \mathrm{~cm})$. Seedlings of Italian ryegrass were counted every three days until no new ones were observed.

\subsection{Seedling survival and reproductive traits}

This experiment was performed to assess the influence of the emergence timing on seedling survival to mature plants and reproductive traits.

A field experiment was conducted in RBD with four replicates in a factorial arrangement. The first factor was two Italian ryegrass populations (susceptible and resistant); the second factor was three cohorts (March, April, and June), simulating an Italian ryegrass natural emergence (Maia et al., 2008). For seedling development, in a greenhouse, seeds were sown in 294 cell plastic trays in three timings: 14/03/2018 (cohort 1), 14/04/2018 (cohort 2 ), and 19/05/2018 (cohort 3). After the emission of the first developed leaf, the seedlings were transferred to the field: 27/03/2018 (cohort 1), 30/04/2018 (cohort 2), and $13 / 06 / 2018$ (cohort 3 ). Fifty seedlings were placed in each plot $(2 \times 1 \mathrm{~m})$. Thus, each cohort represented specific periods in a year.

Survival assessment was carried out weekly up to the onset of seed production, and the reproductive traits (spikes per plant, spikelets per spikes, and flowers per spikelets) were determined in 10 plants randomly selected in the central area of each plot

\subsection{Density-dependent effect on fecundity}

To quantify the effect of intraspecific density on fecundity, a specific experiment was conducted. The 
experiment was conducted in RBD with four replications in a factorial arrangement. The first factor was two Italian ryegrass populations (susceptible and resistant), and the second factor by a range of plant density $(1,10,15,30,50$ plants $\mathrm{m}^{-2}$ ). Ten plants per plot were randomly collected at the end of the plant cycle, and the number of seeds per spikelet was counted.

The relationship between L. multiflorum density and fecundity was established through the hyperbolic model (Cousens et al., 1986).

$$
S=\frac{f}{(1+a X)}
$$

Where $\boldsymbol{S}$ is the number of seeds produced per plant (seeds $\mathrm{m}^{-2}$ ), $\boldsymbol{X}$ is the density of plants (plants $\mathrm{m}^{-2}$ ), $\boldsymbol{f}$ is the maximum number of seeds produced per plant when the plant density approaches zero, and $\boldsymbol{a}$ is the area required by the plant to produce seeds.

\subsection{Statistical analysis}

An analysis of variance was conducted to check the effect of populations and cohorts on seedling emergence and reproductive traits $(p<0.05)$, using ExpDes.pt package (Ferreira et al., 2014) available for R (R Core Team 2018).

A survival analysis based on the Log Rank test (Rousseaux, Gad, 2013). was carried out to test for cohort effects on survival to the adult stage. for susceptible and resistant biotypes. Multiple pairwise comparisons among cohorts were based on the Holm-Sidak test ( $\mathrm{p} 0.05)$. Both were performed using Sigmaplot v.12.

The density-dependent model (eqn 1) was fitted to the data set with the " $n l s$ " package available for $\mathrm{R}$, the goodness of fit was assessed using the root mean square error (RMSE) and the pseudo determination coefficient $\left(\mathrm{pR}^{2}\right)$ ( $\mathrm{R}$ Core Team 2018).

\section{Results and discussion}

\subsection{Seedling emergence pattern}

The average final emergence rate of susceptible and resistant populations was $72.3 \%$ ( \pm 0.4 ; standard deviation) and $72.8 \%$ ( \pm 0.5$)$, respectively. As no statistical differences were observed $(p<0.05)$, the data were grouped. Therefore, the average emergence rate observed was $72.5 \%$ ( \pm 0.4$)$. Emergence started at 16 days after L. multiflorum sowing, reaching $50 \%$ total emergence between 25 and 28 days and $90 \%$ at 37 days (Figure 2). The emergence started when the accumulated rainfall reached $30 \mathrm{~mm}$. For L. rigidum, it has been suggested that rainfall of at least $10 \mathrm{~mm}$ is required for seedlings emergence (Fernandez-Quintanilla et al., 2000).

The average seedling recruitment was higher than that reported by other authors (40\%) (Ichihara et al.,

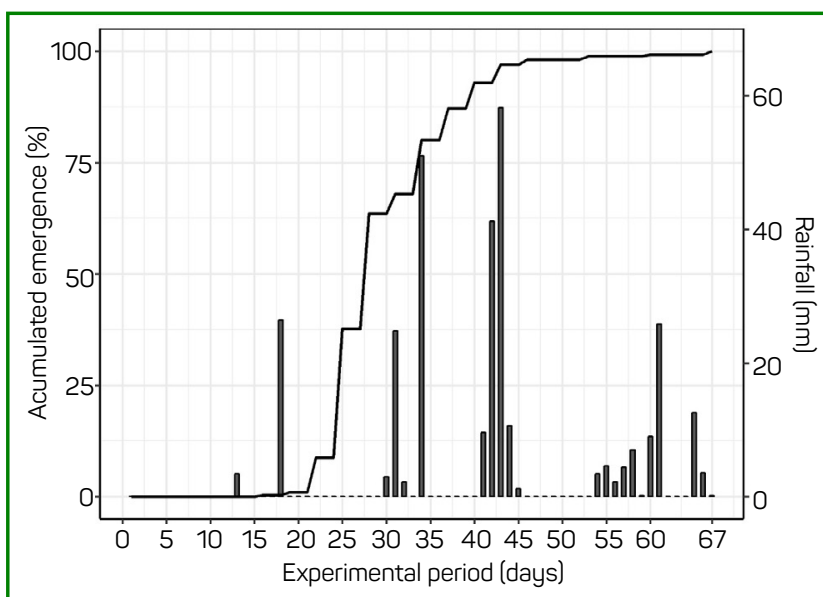

Figure 2 - Rainfall ( - ) and cumulative emergence (-) of Italian ryegrass.

2010; Maia et al., 2009). In this study, the seeds were placed at a depth of $1 \mathrm{~cm}$ in the soil which might have favored emergence, mainly because they are photoblastic positive (Deregibus et al., 1994). However, in species of the genus Lolium, it has been observed that the emergence is the same in seeds positioned up to 5 $\mathrm{cm}$ soil but reduced at higher depths (Arnott, 1969). It is vital to notice that a large proportion (90\%) of Italian ryegrass seeds is found in $5 \mathrm{~cm}$ depth in the conservation system (e.g., no-till system) (Ichihara et al., 2010). These results suggest the high and rapid emergence of Italian ryegrass seedlings under appropriate environmental conditions.

The results of this study showed that the emergence rate did not differ between populations (susceptible and resistant). However, several studies have characterized the differential emergence between glyphosate-resistant and -susceptible populations in different weed species (Giacomini et al., 2014; Fernández-Moreno et al., 2017). In these studies, a lower emergence of resistant populations is commonly observed compared to the susceptible one, of up to $20 \%$ in Italian ryegrass. The mechanism responsible for the herbicide resistance can directly influence seedling emergence dynamics (Délye et al., 2013).

\subsection{Seedling survival and reproductive traits}

There was no statistical difference between the susceptible and resistant populations in same cohorts (Table 3). The first two cohorts of the populations presented similar survival rates, with 0.02 and 0.03 for the susceptible one and 0.04 and 0.05 for the resistant one (Figure 3, Table 2). The third cohort displayed a higher survival rate than the first two, this being 0.10 and 0.16 for susceptible and resistant populations, respectively (Table 2). 
The log-rank analysis confirmed a significant difference between the survival curves $\left(\mathrm{X}^{2}=32.86, g l=5, p<0.01\right.$; Figure 3), with a higher plant survival of the third cohort compared to the first two (Holm-Sidak test, $p<0.05$; Table 3). It should be noted that within the same cohort, no

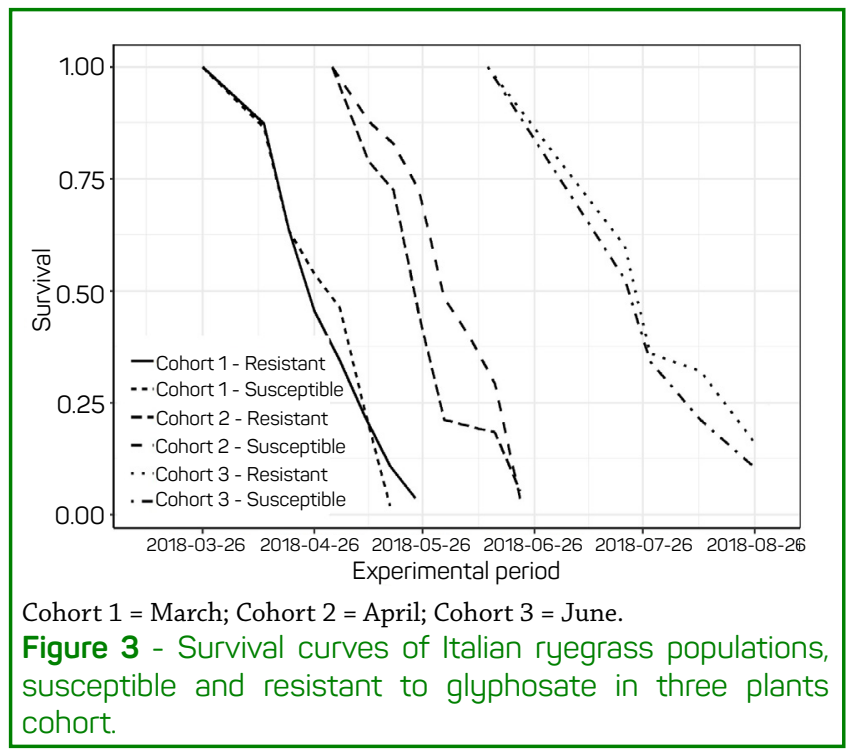

Table 2 - Mean survival rate of glyphosate-resistant and susceptible Italian ryegrass populations in the three plants cohorts.

\begin{tabular}{l|c|c|c|}
\hline Cohort & Population & Survival & SE $^{*}$ \\
\hline \multirow{2}{*}{1} & Susceptible & 0.02 & 0.020 \\
\hline \multirow{2}{*}{2} & Resistant & 0.04 & 0.020 \\
\hline \multirow{2}{*}{3} & Susceptible & 0.03 & 0.020 \\
\hline & Resistant & 0.05 & 0.020 \\
\hline * & Susceptible & 0.10 & 0.049 \\
\hline
\end{tabular}

* Standard error.

Cohort 1 = March; Cohort 2 = April; Cohort 3 = June

Table 3 - Comparison by pairwise on survival rate between glyphosate-resistant and susceptible Italian ryegrass populations in the three plant cohorts.

\begin{tabular}{lcc|c}
\hline Comparisons & Statistic & $p$ value \\
\hline C1susceptible vs. C1resistant & 0.0011 & 0.9700 \\
\hline C2susceptible vs. C2resistant & 4.6500 & 0.2000 \\
\hline C3susceptible vs. C3resistant & 0.5700 & 0.9100 \\
\hline C1susceptible vs. C2susceptible & 0.076 & 0.9500 \\
\hline C1susceptible vs. C3susceptible & 7.8800 & $0.0490^{*}$ \\
\hline C2susceptible vs. C3susceptible & 7.4900 & $0.0480^{*}$ \\
\hline C1resistant vs. C2resistant & 3.0300 & 0.3500 \\
\hline C1resistant vs. C3resistant & 9.6400 & $0.0240^{*}$ \\
\hline C2resistant vs. C3resistant & 16.1800 & $0.0008^{*}$ \\
\hline
\end{tabular}

* Significant to $p \leq 0.05$.

Cohort 1 = March; Cohort 2 = April; Cohort $3=$ June difference was observed between susceptible and resistant populations to glyphosate (Table 3). Several studies have reported different survival rates between cohorts. For instance, $C$. bonariensis, survival rate ranges from 0.44 to 0.13; Salsoa australis from 0.75 to 0 and Digitaria sanguinalis from 0.2 to 0.003 (Borger, et al., 2009; Oreja et al., 2012; Zambrano-Navea et al., 2018). The difference in survival can be explained by the different establishment times. In general, earlier cohorts exert an intense competition (intraspecific) on the following ones (Radosevich et al., 2007; Borger et al., 2009). In this work, the mean survival rate was similar between the first and second cohort but lower than the third cohort. In the first 60 days after each cohort was established, the accumulated precipitation was 127,174 , and $126 \mathrm{~mm}$, while the accumulated thermal sum was 891,690 , and $643{ }^{\circ} \mathrm{C}$, respectively for cohorts 1,2 , and 3 . The higher survival rate of the third cohort could be attributed mainly to the rainfall distribution, as shown in Figure 1, favoring plant growth.

No statistical difference was observed between glyphosate-resistant and susceptible populations in the reproductive traits evaluated $(p<0.05$, so that the data were pooled. The number of spikes (spk) per plant did not show significant differences between the first $(50.34 \pm$ $\left.2.72 \mathrm{spk} \mathrm{pl}^{-1}\right)$ and the second cohort $\left(47.02 \pm 3.44 \mathrm{spk} \mathrm{pl}^{-1}\right)$; however, the third produced $40 \%$ fewer spikes (27.27 $\pm 3.18 \mathrm{spk} \mathrm{pl}^{-1}$ ) (Figure 4). For the spikelets (spklt) per spike, no significant differences were observed between the three cohorts $(24.29 \pm 0.43,26.15 \pm 0.6,24.29 \pm 0.79$ spklt spk $\mathrm{s}^{-1}$ for cohorts 1, 2, and 3, respectively) (Figure 4). The number of flowers (flwrs) per spikelet was similar between the first two plant cohorts $(11.33 \pm 0.16,12.12 \pm$ 0.38 flwrs spklt ${ }^{-1}$, cohort 1 and 2, respectively); however, they were $11 \%$ smaller than those of the third cohort (13.17 \pm 0.36 flwrs spklt $^{-1}$ ) (Figure 4).

The number of spikes per plant ranged was lower than observed by Bararpour et al. (2017), who reported between 100 and 153 spikes per plant in L. multiflorum. As well as survival, reproductive traits can also be affected by the cohort's establishment, as already seen with different weeds (Green, 2010; Torra, Recasens, 2008). The fecundity of C. bonariensis decreased by $89 \%$ in cohorts that established themselves later, compared to earlier ones (ZambranoNavea et al., 2018). Difference between reproductive traits was observed only for the number of spikes per plant and flowers per spikelet. The number of spikes per plant is the most influenceable character that according to the cohort establishment (40\%) because it is dependent on the number of tillers, which is strongly affected by environmental factors (Barth Neto et al., 2013). Different from what is observed in this study, several studies have shown differences in reproductive traits between populations susceptible and resistant to glyphosate in plants of the genus Lolium (Vargas et al., 2005; Yanniccari et al. 2016), and those difference commonly characterize the lower production of the determined trait in resistant plants. 


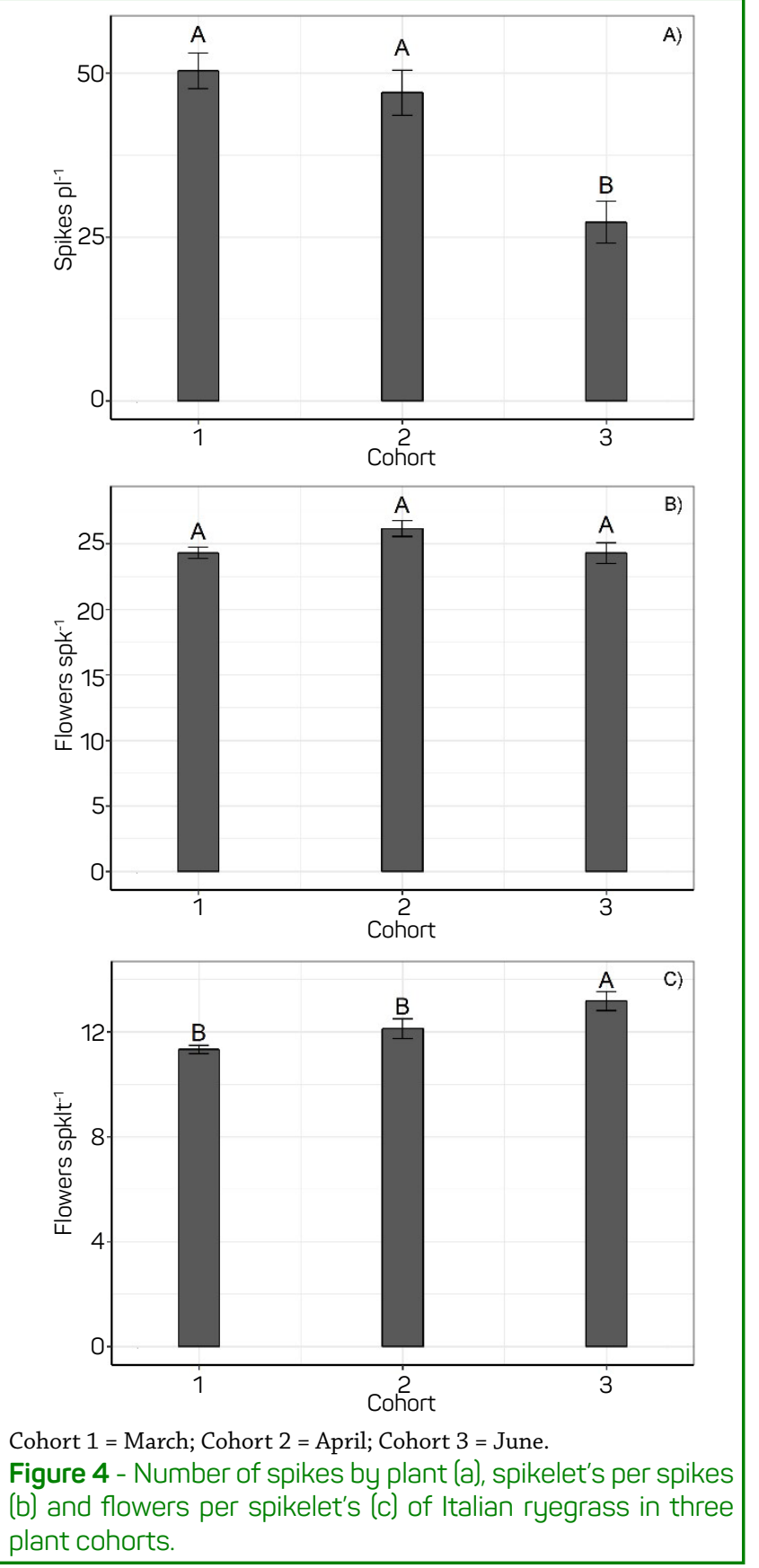

\subsection{Effect of density on fecundity}

For glyphosate-resistant and susceptible populations, the rectangular hyperbolic model showed a good fit (Figure 5, Table 4), demonstrating that their seed production was density-dependent, reaching a $90 \%$ reduction when the density was 50 plants $\mathrm{m}^{2}$ and similar to that observed with L. rigidum (Gonzalez-Andujar, Fernandez-Quintanilla, 2004). Density-dependence regulation has been observed in many weeds such as Avena sterilis, L. rigidum, D. sanguinalis or C. bonariensis (Gonzalez-Andujar, Fernandez-Quintanilla, 2004; Oreja et al., 2012; Zambrano-Navea et al., 2018).
The maximum seed production per plant $(f)$ differed between populations (resistant and susceptible), being higher in the susceptible $\left(20,300 \pm 1,212\right.$ seeds plant $\left.{ }^{-1}\right)$ when compared to the resistant population $(13,830 \pm$ 1,305 seeds plant ${ }^{-1}$ ) (Table 4). The difference in potential seed production between glyphosate-resistant and susceptible populations has also been described in the genus Lolium. A glyphosate-susceptible population from Spain was documented to produce 8,000 seeds plant ${ }^{-1}$, whereas glyphosate-resistant plants produced 5,000 seeds plant $^{-1}$ (Fernández-Moreno et al., 2017). Similar results were observed with $L$. perenne from Argentina, in which a glyphosate-susceptible biotype produced 7,500 seeds plant $^{-1}$ while resistant plants produced 5,000 seeds plant ${ }^{-1}$ (Yanniccari et al., 2016).

The comparison between glyphosate-resistant and susceptible Italian ryegrass populations in this study showed few differences between them at the demographic level. They were characterized mainly by their potential for seed production per plant under low population density. Several biological and molecular factors may be involved

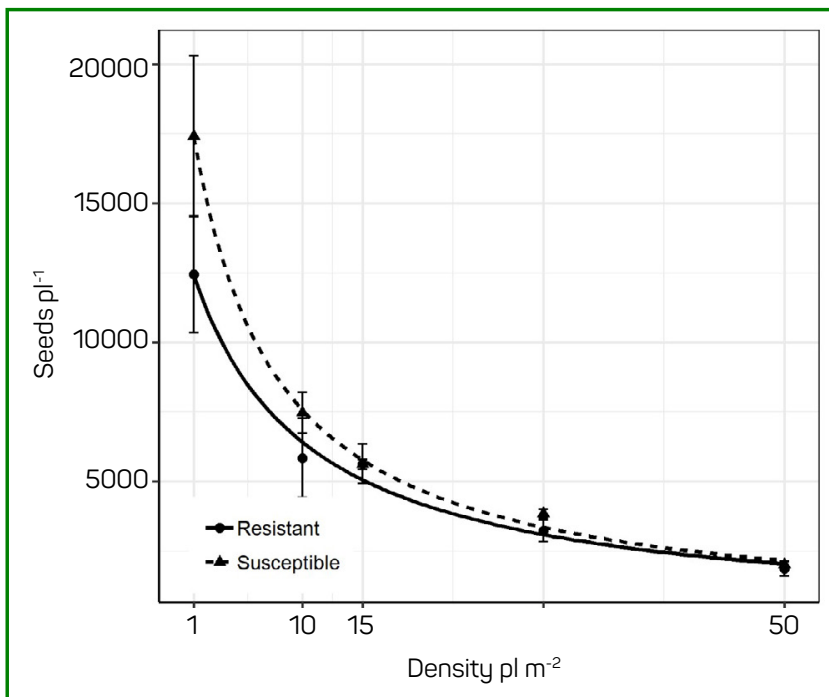

Figure $\mathbf{5}$ - Effect of plant density on the seed production on glyphosate-resistant and susceptible Italian ryegrass populations fitted to the hyperbolic model. The parameters of equations are showed in Table 4.

Table 4 - Equations parameters for the rectangular hyperbolic model (eqn 1). Maximum seed production capacity per plant $(f)$ and area required to produce seeds (a), root mean square error (RMSE) and pseudo coefficient of determination $\left(\mathrm{pR}^{2}\right)$, for glyphosate-resistant and susceptible Italian ryegrass populations.

\begin{tabular}{lcccc}
\multirow{2}{*}{ Populations } & \multicolumn{2}{c}{ Parameters } & \multirow{2}{*}{ RMSE } & pR $^{2}$ \\
\cline { 2 - 3 } & $f^{*}$ & 0 & & \\
\hline Susceptible & $20,300.00\left(1,212.00^{\#}\right)$ & $0.17(0.03)$ & 110.50 & 0.97 \\
Resistant & $13,830.00(1,305.00)$ & $0.12(0.03)$ & 136.00 & 0.89 \\
\hline
\end{tabular}

"Values in brackets indicate the standard error. 
in the fitness cost in glyphosate-resistant plants. However, the main one is believed to be related to the reduction in the catalytic efficiency of EPSPS due to mutations that cause changes in enzyme structure (Vila-Aiub et al., 2019), as observed with Eleusine indica (Yu et al., 2015).

In-depth knowledge of weed biology could provide practical solutions in the field (Van Acker, 2009), but the results obtained in this work could also help to establish better weed management strategies for Italian ryegrass.

\section{Conclusions}

This study allows us to conclude that under appropriate environmental conditions, the Italian ryegrass plants emerge fast. The period when they are established in the field has a direct effect on plant survival and reproductive traits (spikes per plant and flowers per spikelet). The first and second cohorts showed a lower survival rate when compared to the last one; however, they had a greater potential for spike production per plant. The third cohort exhibited more potential for flower production per spikelet than the first two. Italian ryegrass has a high seed production potential but can be severely affected by intraspecific competition.

\section{Author' contributions}

JGA, and MMT: conceived and supervised the study. HMS, $\mathrm{KCH}$, and PBP: assisted in experiments development and data collection. FP: conducted the data analysis. FP, JGA, and MMT: wrote the manuscript. MMT: contributed to funding acquisition. All authors contributed critically to the drafts and gave final approval for the publication.

\section{Funding}

The authors are grateful to the Coordenação de Aperfeiçoamento de Pessoal de Nível Superior (Capes), Universidade Tecnológica Federal do Paraná (UTFPR) and Instituto de Agricultura Sostenible Consejo Superior de Investigaciones Científicas (IAS-CSIC) for the infrastructure and financial support.

\section{References}

Arnott RA. The effect of seed weight and depth of sowing on the emergence and early seedling growth of perennial ryegrass (Lolium perenne). Grass For Sci. 1969;24(2):104-10. Available from: https://doi. org/10.1111/j.1365-2494.1969.tb01053.x

Bararpour MT, Norsworthy JK, Burgos NR, Korres NE, Gbur EE. Identification and biological characteristics of ryegrass (Lolium spp.) accessions in Arkansas. Weed Sci. 2017;65(3):350-60. Available from: https://doi.org/10.1017/wsc.2016.28

Barth Neto A, Carvalho PCF, Lemaire G, Sbrissia AF, Canto MWD, Savian JV et al. [Tillering in Italian ryegrass established after soybean or corn, under different stockings and grazing intensities]. Pesq Agropec. 2013;48(3):329-38. Portuguese. Available from: https://doi. org/10.1590/S0100-204X2013000300012

Borger CPD, Scott JK, Walsh M, Powles SB. Demography of Salsolo australis populations in the agricultural region of south-west Australia. Weed Res. 2009;49(4):391-9. Available from: https://doi. org/10.1111/j.1365-3180.2009.00702.x

Cousens R, Doyle CJ, Wilson BJ, Cussans GW. Modelling the economics of controlling Avena fotua in winter wheat. Pest Sci. 1986;17(1):1-12. Available from: https://doi.org/10.1002/ps.2780170102

Délye C, Menchari Y, Michel S, Cadet E, Le Corre V. A new insight into arable weed adaptive evolution: mutations endowing herbicide resistance also affect germination dynamics and seedling emergence. Ann Bot. 2013;111(4):681-91. Available from: https://doi.org/10.1093/aob/mct018

Deregibus VA, Casal JJ, Jacobo EJ, Gibson D, Kauffman M, Rodriguez AM. Evidence that heavy grazing may promote the germination of Lolium multiflorum seeds via phytochrome-mediated perception of high red/far-red ratios. Funct Eco. 1994;8(4):536-42. Available from: https://doi.org/10.2307/2390079
Fernández-Moreno PT, Alcántara-de la Cruz R, Smeda RJ, Prado R. Differential resistance mechanisms to glyphosate result in fitness cost for Lolium perenne and L. multiflorum. Front Plant Sci. 2017;8:1-16. Available from: https://doi.org/10.3389/fpls.2017.01796

Fernandez-Quintanilla C, Barroso J, Recasens J, Sans X, Torner C, Arco MJS. Demography of Lolium rigidum in winter barley crops: analysis of recruitment, survival and reproduction. Weed Res. 2000;40(3):281-91. Available from: https://doi.org/10.1046/j.1365-3180.2000.00187.x

Ferreira EB, Cavalcanti PP, Nogueira DA. ExpDes: an R package for Anova and experimental designs. Appl Math. 2014;5(19):1-8. Available from: https://doi.org/10.4236/am.2014.519280

Giacomini D, Westra P, Ward SM. Impact of genetic background in fitness cost studies: an example from glyphosate-resistant Palmer amaranth. Weed Sci. 2014;62(1):29-37. Available from: https://doi. org/10.1614/WS-D-13-00066.1

Gonzalez-Andujar JL, Fernandez-Quintanilla C. Modelling the population dynamics of annual ryegrass (Lolium rigidum) under various weed management systems. Crop Prot. 2004;23(8):723-9. Available from: https://doi.org/10.1016/j.cropro.2003.12.007

Gonzalez-Andujar JL, Fernandez-Quintanilla C, Bastida F, Calvo R, Gonzalez-Diaz L, Izquierdo $\mathrm{J}$ et al. Field evaluation of a decision support system for herbicidal control of Avena sterilis ssp. Iudoviciono in winter wheat. Weed Res. 2010;50(1):83-8. Available from: https://doi. org/10.1111/j.1365-3180.2009.00744.x

Green TD. The ecology of fleabane (Conyza spp.) [thesis]. Armidale: University of New England; 2010.

Ichihara M, Yamashita M, Sawada $H$, Ishida $Y$, Inagaki $H$, Kida $Y$ et al. [Dynamics of seedbank and seedling emergence of Italian ryegrass 
(Lolium multiflorum Lam.) in wheat-soybean double cropped fields: a comparison between tilled and no-till systems]. J Weed Sci Tech. 2010;55(1):16-25. Japanese. Available from: https://doi.org/10.3719/ weed.55.16

Maia FC, Maia MS, Bekker RM, Berton RP, Caetano LS. Lolium multiflorum seeds in the soil: I soil seed bank dynamics in a no til system. Rev Bras Sementes. 2008;30(2):100-10. Available from: https:// doi.org/10.1590/S0101-31222008000200013

Maia FC, Maia MS, Bekker RM, Berton RP, Caetano LS. Lolium Multiflorum seeds in the soil: II longevity under natural conditions. Rev Bras Sementes. 2009;31(2):123-8. Available from: https://doi.org/10.1590/ S0101-31222009000200014

Oreja FH, Bastida F, Gonzalez-Andujar JL. Simulation of control strategies for decision-making regarding Digitoria songuinalis in glyphosate-resistant soybeans. Cienc Inv Agr. 2012;39(2):299-308. Available from: https://doi.org/10.4067/S0718-16202012000200006

Peel MC, Finlayson BL, McMahon TA. Updated world map of the Köppen-Geiger climate classification. Hydrol Earth Syst Sci. 2007;4(2):43973. Available from: https://doi.org/10.5194/hess-11-1633-2007

Radosevich SR, Holt JS, Ghersa CM. Ecology of weeds and invasive plants: relationship to agriculture and natural resource management. 3th ed. New Jersey: John Wiley \& Sons; 2007.

R Core Team. R: a language and environment for statistical computing. Vienna: R Foundation for Statistical Computing; 2018[access 0301 2019]. Available from: https://www.R-project.org/

Rousseaux CG, Gad SC. Chapter 30: statistical assessment of toxicologic pathology studies. Hasch Rouss Hand Toxicol Path. 2013;2:893-988. Available from: https://doi.org/10.1016/B978-0-12-415759-0.00030-3

Torra J, Recasens J. Demography of corn poppy (Popover rhoeos) in relation to emergence time and crop competition. Weed Sci. 2008;56(6):82633. Available from: https://doi.org/10.1614/WS-07-077.1
Trusler CS, Peeper TF, Stone AE. Italian ryegrass (Lolium multiflorum) management options in winter wheat in Oklahoma. Weed Tech. 2007;21(1):151-8. Available from: https://doi.org/10.1614/WT-06-038.1

Van Acker RC. Weed biology serves practical weed management. Weed Res. 2009;49(1):1-5. Available from: https://doi.org/10.1111/j.13653180.2008.00656.x

Vargas L, Roman ES, Rizzardi MA, Silva VC. [Change in the biological characteristics of ryegrass (Lolium multiflorum) biotypes caused by resistance to the herbicide glyphosate]. Planta Daninha. 2005;23(1):153-60. Portuguese. Available from: https://doi. org/10.1590/S0100-83582005000100018

Vila-Aiub MM, Yu Q, Powles SB. Do plants pay a fitness cost to be resistant to glyphosate? New Phytol. 2019;223(2):532-47. Available from: https://doi.org/10.1111/nph.15733

Weed Science. The international survey of herbicide-resistant weeds database. Weed Science Online. 2020[access April 2, 2020]. Available: https://www.weedscience.org

Yanniccari M, Vila-Aiub M, Istilart C, Acciaresi H, Castro AM. Glyphosate resistance in perennial ryegrass (Lolium perenne L.) is associated with a fitness penalty. Weed Sci. 2016;64(1):71-9. Available from: https://doi. org/10.1614/WS-D-15-00065.1

Yu Q, Jalaludin A, Han H, Chen M, Sammons RD, Powles SB. EvoIution of a double amino acid substitution in the 5-enolpyruvylshikimate-3-phosphate synthase in Eleusine indica conferring high level glyphosate resistance. Plant Phys, 2015;167(4):1440-7. Available from: https://doi.org/10.1104/pp.15.00146

Zambrano-Navea C, Bastida F, Gonzalez-Andujar JL. Demography of Conyzo bonariensis (Asteraceae) in a ruderal mediterranean habitat. Phytoparasitica. 2018;46:263-72. Available from: https://doi.org/10.1007/ s12600-018-0647-9 